\title{
LETTER TO THE EDITOR (JUNE 10,2017) CONCERNING THE PAPER "TRENDS IN SMOKING AMONG SECONDARY SCHOOL AND HIGH SCHOOL STUDENTS IN POLAND, 2009 AND 2011"
}

Dear Editor,

I am very impressed by the article by Wojtyła-Buciora et al. entitled "Trends in smoking among secondary school and high school students in Poland, 2009 and 2011" that was published in the "International Journal of Occupational Medicine and Environmental Health" in 2017 [1]. The authors conducted a questionnaire survey to determine the age of smoking initiation along with smoking rates [1]. The authors also evaluated smoking trends for secondary and high school students during 2009 and 2011. Rates of secondary school students smoking at least once in their lifetime were $9 \%$ in 2009 and $11 \%$ in 2011. In addition, rates of high school students smoking at least once in their lifetime were $15 \%$ in 2009 and $24 \%$ in 2011. Moreover, the rate of daily smoking among smokers was $50 \%$ in 2009 , and rates of daily smoking among smokers in 2011 were $30 \%$ in secondary school and 49\% - in high school, respectively. I have some concerns about their study.

Firstly, Polańska et al. examined factors of smoking susceptibility by means of a cross-sectional study [2]. They handled 3552 responses from 4050 students, and the number of non-smokers, who had responded, was 2508. Males, older students, lack of mothers' high educational levels were risks for future smoking. Students who lived in households with no smoking ban and those who had ever tried cigarettes were factors of smoking susceptibility. In addition, students having smoking friends, seeing school personnel smoking on the school premises, perceiving smoking girls more attractive, and no school training on tobacco harm were also factors of smoking susceptibility. Racic et al. also identified the determinants of smoking initiation among high school students [3]. About $45 \%$ of fourth-grade students initiated smoking, which was higher than second- and third-grade students. A multivariate analysis showed that males, smoking susceptibility, smoking habit of parents and friends were factors of smoking initiation. As these 2 pieces of literature showed, the home environment and social surroundings contributed to tobacco use. Wojtyła-Buciora et al. [1] presented trends in smoking among secondary school and high school students, which should be evaluated by considering factors of smoking susceptibility and initiation.

Secondly, Veeranki et al. estimated prevalence and correlates of smoking initiation among adolescents [4]. Prevalence of smoking initiation ranged from $0.7 \%$ at 10 or 11 years of age to $9.6 \%$ at 12 or 13 years of age. In addition, males, exposures to parental or peer smoking and industry promotions were significant predictors for smoking initiation. O'Loughlin et al. also identified predictors of smoking initiation among children, aged 11-13 years old (early adolescence), 13-15 years old (middle adolescence), and 15-17 years old (late adolescence), respectively [5]. Friends' smoking was a risk in early adolescence and lost potency was a risk in late adolescence. 
Although depressive symptom was selected as a risk in early and middle adolescence, it was selected as a preventive factor in late adolescence. These reports presented the change in the risk factors of smoking initiation during the adolescents, which should be specified by further study.

Thirdly, Daly and Egan reported the relationship between early cognitive ability and smoking habits with special reference to educational attainment [6]. Educational attainment explained approximately a half of the association between childhood cognitive ability and smoking initiation/ cessation. Educational attainment would lead to lower rates of smoking initiation and increased rates of smoking cessation. There is an association among educational attainment, anxiety/depression and cognitive ability [7], and I suspect that biological and socio-economic factors should concurrently be included to explore predictors of smoking initiation among adolescents. At this point, Lacey et al. observed a significant effect of childhood socio-economic position (SEP) on subsequent smoking status by adjusting childhood cognitive ability and educational attainment [8]. Socio-economic position related to social environment and lifestyle factors, and it also related to childhood self-control. Daly et al. clarified that childhood self-control was positively related to smoking cessation and negatively related to smoking initiation [9]. Namely, smoking initiation among adolescents was closely related to comprehensive psycho-social factors.

More than 2 decades ago, a recommendation of 5 steps to prevent tobacco use among adolescents was made [10]. I think that fundamental approach has not changed, although ethnic difference seems important for predicting factors of smoking initiation among adolescents.

\section{ACKNOWLEDGMENTS}

I appreciate the members of the Department of Hygiene and Public Health, Nippon Medical School, Tokyo, Japan, for their technical support and advice.
Key words:

Smoking, Secondary school, High school, Time trends, Predictors,

Prevention

\section{REFERENCES}

1. Wojtyła-Buciora P, Stawińska-Witoszyńska B, ŻukiewiczSobczak W, Wojtyła C, Biliński P, Urbaniak M, et al. Trends in smoking among secondary school and high school students in Poland, 2009 and 2011. Int J Occup Med Environ Health. 2017;30(5):763-73, https://doi.org/10.13075/ijomeh. 1896.00741.

2. Polańska K, Wojtysiak P, Bąk-Romaniszyn L, Kaleta D. Susceptibility to cigarette smoking among secondary and high school students from a socially disadvantaged rural area in Poland. Tob Induc Dis. 2016;14:28, https://doi.org/10.1186/ s12971-016-0092-9.

3. Racic M, Tanovic S, Joksimovic VR, Joksimovic BN, Ristic S. Prevalence and determinants of smoking initiation among school students in Bosnia and Herzegovina. Int J Adolesc Med Health. 2015;27(4):397-403, https://doi.org/10.1515/ ijamh-2014-0041.

4. Veeranki SP, John RM, Ibrahim A, Pillendla D, Thrasher JF, Owusu D, et al. Age of smoking initiation among adolescents in Africa. Int J Public Health. 2017;62(1):63-72, https://doi. org/10.1007/s00038-016-0888-7.

5. O'Loughlin J, O'Loughlin EK, Wellman RJ, Sylvestre MP, Dugas EN, Chagnon M, et al. Predictors of cigarette smoking initiation in early, middle, and late adolescence. J Adolesc Health. 2017;61(3):363-70, https://doi.org/10.1016/j.jadohealth.2016.12.026.

6. Daly M, Egan M. Childhood cognitive ability and smoking initiation, relapse and cessation throughout adulthood: Evidence from 2 British cohort studies. Addiction. 2017;112(4):651-9, https://doi.org/10.1111/add.13554.

7. Yang JJ, Song M, Yoon HS, Lee HW, Lee Y, Lee SA, et al. What are the major determinants in the success of smoking cessation: Results from the Health Examinees Study. PLoS One. 2015;10(12):e0143303, https://doi.org/10.1371/journal. pone. 0143303 . 
8. Lacey RE, Cable N, Stafford M, Bartley M, Pikhart H. Childhood socio-economic position and adult smoking: Are childhood psychosocial factors important? Evidence from a British birth cohort. Eur J Public Health 2011;21(6):725-31, https://doi.org/10.1093/eurpub/ckq179.

9. Daly M, Egan M, Quigley J, Delaney L, Baumeister RF. Childhood self-control predicts smoking throughout life: Evidence from 21,000 cohort study participants. Health Psychol. 2016;35(11):1254-63, https://doi.org/10.1037/hea0000393.

10. Epps RP, Manley MW. Prevention of tobacco use during childhood and adolescence. Five steps to prevent the onset of smoking. Cancer. 1993;72(3 Suppl):1002-4, https:// doi.org/10.1002/1097-0142(19930801)72:3+<1002::AIDCNCR2820721309>3.0.CO;2-G.

Tomoyuki Kawada Nippon Medical School, Tokyo, Japan Department of Hygiene and Public Health 1-1-5 Sendagi, Bunkyo-Ku Tokyo 113-8602, Japan (e-mail: kawada@nms.ac.jp)

This work is available in Open Access model and licensed under a Creative Commons Attribution-NonCommercial 3.0 Poland License - http://creativecommons.org/ licenses/by-nc/3.0/pl/deed.en. 